\title{
Indexing of ONKOLOGIE in Index Medicus / MEDLINE
}

A t the beginning of 2001 it is a great pleasure for the Editorial Board of ONKOLOGIE to inform its readers that our journal has been re-listed in Index Medicus and its online counterpart MEDLINE, starting with the issue of 05/2000. Cited and indexed are abstracts of articles as well as editorials and letters to the editor. The decision to index a biomedical journal for these publications is made by the Director of the National Library of Medicine, $\mathrm{NIH}$ Bethesda, based on considerations of both scientific policy and quality. From time to time, listed biomedical journals are re-reviewed by a 'L iterature Selection Technical R eview Committee'. A s a result of a review in 1992, ONKOLOGIE was deselected from the list in 1993 due a decline in quality at the beginning of the 1990s. The Editorial Board of the journal was well aware that it needed to achieve the re-listing in this world-wide bibliographic database by improving the quality, originality and importance of ONKOLOGIE's scientific content. In this context it was decided that all editorials, scientific reviews and original papers had to be published in English. The peer review process was extended to all incoming manuscripts containing scientific research. Therefore today not only all original articles, but also all reviews are only published after approval by two independent reviewers.

The term of service for members of the Editorial Board was restricted to 5 years, the one for members of the Scientific Committee to 3 years. It is only extended when these members actively contribute to the form of the journal.

The journal has become as well a forum for Austria and Switzerland, and an effort has been made to ensure that the complete range of oncological departments is represented on the editorial board.

A II these measures in the course of the 1990s led to a continuous improvement in quality, and today, ONKOLOGIE is one of the leading clinically oriented oncological journals in Central Europe. We start with the premises that cancer is a disease not limited by borders of medical branches, that the patient suffering from cancer must be treated in various oncological disciplines, and that multimodal treatment options become increasingly important. It follows therefore that we highlight and strongly encourage work that reveals the benefits of interdisciplinary approaches.

In January 1999 the E ditorial B oard applied for re-examination of ONKOLOG IE in Index M edicus / MEDLINE, which was approved of in 0 ctober 2000.

In this context the E ditorial B oard wants to emphasize that relisting is the result of a scientific cooperate effort, and to take the opportunity to thank the numerous authors who submitted articles of great quality during past years. Thanks come not only from those responsible for the contents of the journal, but also from those who produce it - Karger Publishers. R elisting I ndex M edicus / MEDLINE offers a major challenge for the near future. At the beginning of the year 2001 we therefore ask all our readers to submit their best original articles to ONKOLOGIE. We in turn guarantee rapid, objective review and timely publication of work that meets high standards $\mathrm{O}$ nly in this way can we sustain and improve the scientific merit of the journal's content, ensuring that the work presented here increasingly gains appropriate international recognition and impact.

For the editors

W. Q ueißer, M annheim

W. Scheithauer, Wien
For the publisher

S. K arger, B asel

\section{KARGER}

Fax +49 7614520714

E-mail Information@K arger.de

www.karger.com (c) 2001 S. K arger G mbH , Freiburg

A ccessible online at:

www.karger.com/journals/onk 